\title{
Asymmetric Carbonyl Reduction with a Supported Ketoreductase
}

Polymer-Supported

Synthesis

\section{Key words}

enzymes

biocatalysis

hydrogenation

ketones

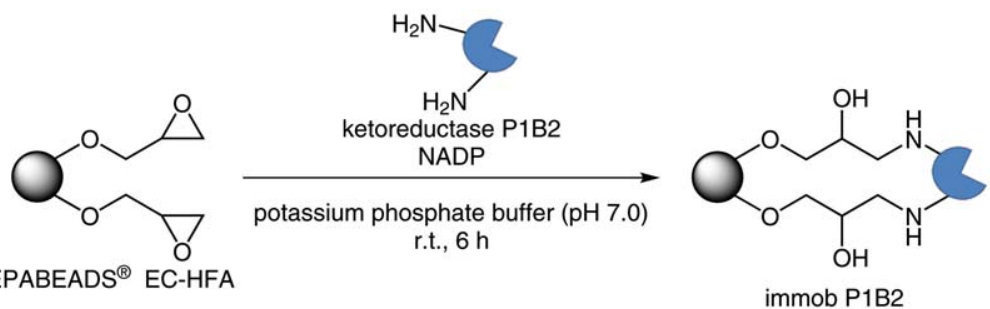
SEPABEADS ${ }^{\circledR}$ EC-HFA

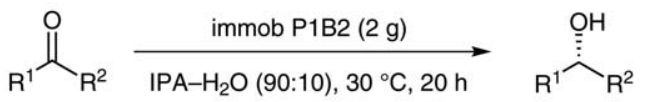<smiles>C[C@H](O)c1cc(C(F)(F)F)cc(C(F)(F)F)c1</smiles>

$100 \%$ conversion $99 \%$ ee<smiles>OC(c1ccc(F)cc1)C(F)(F)F</smiles>

$100 \%$ conversion $93 \%$ ee<smiles>CCOC(=O)C[C@@H](O)c1ccccc1</smiles>

$100 \%$ conversion $>99 \%$ ee<smiles>C[C@H](O)c1ccc(Br)nc1</smiles>

$100 \%$ conversion $>99 \%$ ee<smiles>C[C@H](O)c1ccc(OCC(F)(F)F)nc1</smiles><smiles>O=[N+]1CCCC(O)CC1</smiles>

$100 \%$ conversion $96 \%$ ee<smiles>CC1(C)CC(O)CCO1</smiles>

$92 \%$ conversion $86 \%$ ee<smiles>CC(=O)c1cc(C(F)(F)F)cc(C(F)(F)F)c1</smiles>
\section{hexane-IPA- $\mathrm{H}_{2} \mathrm{O}(50: 40: 10), 40^{\circ} \mathrm{C}$} $(50 \mathrm{~g})$

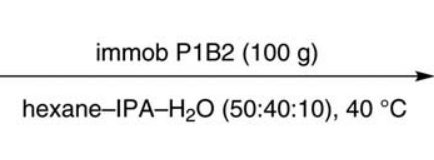<smiles>CC(O)c1cc(C(F)(F)F)cc(C(F)(F)F)c1</smiles>

Significance: Immobilized ketoreductase P1B2 (immob P1B2), prepared as shown in eq. 1, catalyzed the asymmetric transfer-hydrogenation of ketones in 90:10 propan-2-ol-water to give the corresponding alcohols in up to $100 \%$ conversion and up to $>99 \%$ ee (eq. 2). This reaction was used in a $50 \mathrm{~g}$ scale reduction of 3,5-[bis(trifluoromethyl)phenyl]ethanone (1) (eq. 3).

SYNFACTS Contributors: Yasuhiro Uozumi, Kotaro Yamamura Synfacts 2015, 11(10), 1105 Published online: 18.09.2015 Dol: 10.1055/s-0035-1560273; Reg-No.: Y10915SF
Comment: Immob P1B2 was recovered and reused nine times without any loss of its catalytic performance. The catalyst was also used in a flow transfer hydrogenation of ketone $\mathbf{1}$. 